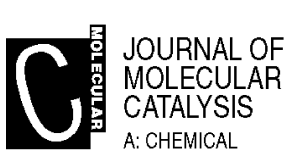

Journal of Molecular Catalysis A: Chemical 149 (1999) 7-23

www.elsevier.com/locate/molcata

\title{
Synthesis and catalytic properties of Ti-substituted SAPO molecular sieves
}

\author{
Bo-Ya Hsu ${ }^{\text {a }}$, Soofin Cheng ${ }^{\text {a, * }}$, Jin-Ming Chen ${ }^{\text {b }}$ \\ a Department of Chemistry, National Taiwan University, Roosevelt Road Sec. 4, Taipei, 106 Taiwan \\ ${ }^{\mathrm{b}}$ Synchrotron Radiation Research Center, Hsinchu, 300 Taiwan
}

Received 13 October 1998; accepted 17 February 1999

\begin{abstract}
The effect of wall polarity on liquid-phase oxidation reactions catalyzed by Ti-substituted SAPO molecular sieves was examined. Titanium and silicon were incorporated into two different aluminophosphate molecular sieves of relatively large pores, namely $\mathrm{AlPO}_{4}-5$ and VPI-5, through hydrothermal synthesis. The synthesized compounds were characterized with XRD, XANES, SEM, Raman, UV-Vis and FT-IR spectroscopies, as well as surface area measurements. The hydrophilicity of aluminophosphate was retained by keeping the $\mathrm{Si} / \mathrm{Al}$ atomic ratio in the synthesis gel at 0.1 . Using hydrogen peroxide as the oxidant, the Ti-substituted SAPO molecular sieves demonstrated marked catalytic activity in phenol hydroxylation reaction. However, little catalytic activity was observed in oxidation of organic substrates of low polarity, such as alkenes. The parameters which might affect the catalytic activities in phenol hydroxylation were investigated. These included the titanium content, the crystalline structure of the catalyst, the relative concentration of the reactants, as well as the polarity of the solvent. The catalytic reactions were considered to proceed mainly on the external surfaces of the aluminophosphate molecular sieves. (C) 1999 Elsevier Science B.V. All rights reserved.
\end{abstract}

Keywords: SAPO; Synthesis; Molecular sieves

\section{Introduction}

The class of microporous materials based on aluminophosphate was discovered by Wilson et al. [1,2] in 1982. In comparison to the $\mathrm{Si}-\mathrm{O}$ bond in zeolites, the Al-O-P bond has more ionic character and is more flexible in bond angle. Therefore, $\mathrm{AlPO}_{4}$-based molecular sieves of a great variety of crystalline structures have been synthesized and affirmed [3,4]. These compounds are isoelectronic to zeolites composed of

\footnotetext{
* Corresponding author
}

$\mathrm{SiO}_{2}$ and the framework is virtually neutral. However, the surface adsorption selectivity of the $\mathrm{AlPO}_{4}$ molecular sieves is reported to be weakly to mildly hydrophilic [5]. For the purpose of promoting the catalytic activities of these molecular sieves, various heterovalent elements have been incorporated into the framework. The modified aluminophosphate molecular sieves were generally found to incorporate negative charges onto the framework, and extra-framework cations are therefore present to balance the charges. In the so-called SAPO-n molecular sieves, a portion of $\mathrm{P}(\mathrm{V})$ is replaced by $\mathrm{Si}(\mathrm{IV})$, while in MAPO-n, portions of $\mathrm{Al}(\mathrm{III})$ 
are replaced by metal ions of +2 oxidation state, such as $\mathrm{Mg}$ (II), $\mathrm{Co}(\mathrm{II})$, etc. [5].

The structure of aluminophosphate molecular sieves, $\mathrm{AlPO}_{4}-5$ with AFI structure (hexagonal symmetry), was affirmed by Bennett et al. [6] in 1983. The framework is built by rings of fourand $\operatorname{six}-\mathrm{TO}_{4}(\mathrm{~T}=\mathrm{Al}$ or $\mathrm{P})$ units. The main channels compose of rings with $12-\mathrm{TO}_{4}(\mathrm{~T}=\mathrm{Al}$ or $\mathrm{P})$ units and an opening of $0.73 \mathrm{~nm}$ diameter. $\mathrm{AlPO}_{4}-5$ has high thermal stability, and it is easy to obtain crystalline phase even incorporating hetero-element into its framework. Hence, there have been many reports concerning the synthesis and characterization of SAPO-5 and MAPO-5 [7,8]. Another aluminophosphate molecular sieve of relative large pore is VPI-5. Its synthesis was first reported in 1988 by Davis et al. [9]. The unidirectional channels are formed by $18 \mathrm{~T}$-membered ring with an internal diameter of $1.2 \mathrm{~nm}$. Many studies have been carried out on this material because its pore diameter is greater than that of commonly used zeolites [10-13].

The substitution of hetero-elements into the framework of molecular sieves was usually reported to create acidic sites, while the incorporation of transition metal elements, such as $\mathrm{Ti}$, $\mathrm{V}, \mathrm{Cr}, \mathrm{Mn}, \mathrm{Fe}$ and $\mathrm{Co}$, endows sites for redox reactions. Ti-substituted zeolites, such as TS-1, Ti-beta, Ti-ZSM-12 were reported to have remarkable redox catalytic activities, particularly in oxidation reactions with hydrogen peroxide as oxidant at mild reaction temperatures [14-20]. In comparison to the syntheses and reaction studies of Ti-substituted silica-based zeolites, only very limited number of reports deals with Ti-substituted aluminophosphate [21-23]. Crystalline aluminophosphates incorporated with titanium were found difficult to obtain, and the maximum Ti-loadings were very low [23]. In order to compare the catalytic properties of Ti-substituted aluminophosphate with that of TS-1, Tuel and Taarit [24,25] have synthesized Ti-substituted SAPO-5. The maximum amount of Ti(IV) loaded into SAPO-5 without formation of $\mathrm{TiO}_{2}$ was reported to be Ti/Si atomic ratio of 0.5 . However, a relatively large amount of $\mathrm{Si}$ was incorporated into SAPO-5, in which the atomic ratio of $\mathrm{Si}: \mathrm{Al}: \mathrm{P}$ is in the range of (0.4-1):1:1. The resultant Ti-substituted SAPO5 was reported to be rather hydrophobic and active as a catalyst in the epoxidation of cyclohexene. In this study, the $\mathrm{Si}$ content in the synthesis gel was maintained at a $\mathrm{Si} / \mathrm{Al}$ atomic ratio of 0.1 in order to retain the hydrophilic character of the aluminophosphate wall. The Ti-substituted SAPO molecular sieves of $\mathrm{AlPO}_{4}-5$ and VPI-5 structures were synthesized with a different procedure and method from those reported by Tuel et al. Especially, the more general and cheaper Al source, pseudoboehmite, was used instead of aluminum isopropyloxide. Samples with various Ti/Al ratios have been prepared and characterized. The catalytic properties of these Ti-SAPO molecular sieves in oxidation of various organic compounds with hydrogen peroxide were studied, and the reaction parameters were examined.

\section{Experimental methods}

\subsection{Synthesis of catalysts}

Titanium and silicon were introduced into the framework of aluminophosphate molecular sieves by adding $\mathrm{Ti}(\mathrm{IV})$ and $\mathrm{Si}$ (IV) species into the synthetic gels before hydrothermal reaction. The Ti-SAPO-5 was synthesized based on the substrate composition of $\mathrm{Al}_{2} \mathrm{O}_{3}: \mathrm{P}_{2} \mathrm{O}_{5}: 0.2 \mathrm{SiO}_{2}$ : (0.04-0.12) $\mathrm{TiO}_{2}: \mathrm{Et}_{3} \mathrm{~N}: 30 \mathrm{H}_{2} \mathrm{O}$, and $\mathrm{Ti}-\mathrm{Si}-$ VPI-5 on the composition of $\mathrm{Al}_{2} \mathrm{O}_{3}: \mathrm{P}_{2} \mathrm{O}_{5}$ : $0.2 \mathrm{SiO}_{2}:(0.02-010) \mathrm{TiO}_{2}: \mathrm{Pr}_{2} \mathrm{NH}: 40 \mathrm{H}_{2} \mathrm{O}$. To an aqueous suspension of pseudoboehmite powder (Vista, $73.5 \% \mathrm{Al}_{2} \mathrm{O}_{3}$ ), a solution of phosphoric acid (Janssen, 85\%) and water in 3:5 weight ratio was added, followed by violent stirring for 3 h. A mixture of TEOS (tetraethyl orthosilicate, Janssen, 98\%) and titanium isopropyloxide (Janssen, 98\%) was then added in drop-by-drop. After stirring for another hour, the organic template was added, which was triethylamine (Jans- 
sen, 99\%) for $\mathrm{AlPO}_{4}-5$ series and dipropylamine (Janssen, 99\%) for the VPI-5 series. The mixture was stirred for $4 \mathrm{~h}$ more. The homogeneous gel was then transferred to an autoclave and crystallized in a pre-heated oven under hydrothermal condition. The temperature and time period of hydrothermal crystallization for TiSAPO-5 series was $200^{\circ} \mathrm{C}, 48 \mathrm{~h}$, and those for Ti-Si-VPI-5 series was $148^{\circ} \mathrm{C}, 40 \mathrm{~h}$. The products were washed with deionized water, filtered, and dried at $50^{\circ} \mathrm{C}$ for $24 \mathrm{~h}$. Ti-SAPO-5 samples were calcined in air at $550^{\circ} \mathrm{C}$ to remove the templating agent.

A TS-1 sample was also prepared and used as the catalyst. Proper amount $(\mathrm{Ti} / \mathrm{Si}$ atomic ratio of 0.03$)$ of $\mathrm{Ti}\left(\mathrm{OC}_{2} \mathrm{H}_{5}\right)_{4}$ was added into a beaker under ice-bath containing $71 \mathrm{ml}$ water. After stirring the solution for $30 \mathrm{~min}, 40 \mathrm{ml}$ of $\mathrm{H}_{2} \mathrm{O}_{2}$ was added slowly to obtain a clear orange solution. The solution was transferred to a flask and $60 \mathrm{~g}$ of colloidal silica was added. The mixture was stirred at room temperature for $2 \mathrm{~h}$ and at $90-100^{\circ} \mathrm{C}$ for another $16 \mathrm{~h} .130 \mathrm{~g}$ of TPAOH was added in. The mixture was stirred at $80^{\circ} \mathrm{C}$ for another $7 \mathrm{~h}$, then transferred to an autoclave and crystallized under $200^{\circ} \mathrm{C}$ for 12 days. The resultant solids were washed thoroughly and calcined at $550^{\circ} \mathrm{C}$, followed by ionexchange with $\mathrm{NH}_{4} \mathrm{Cl}$ solution and calcination again.

\subsection{Catalyst characterization}

The elemental compositions of the samples were analyzed by ICP-AES (Kontron Plasmakon, Model S-35) with HF-dissolved solutions. X-ray diffraction (XRD) patterns were obtained using a Scintag X1 diffractometer with $\mathrm{CuK} \alpha$ radiation. Infrared spectra were recorded with a Bomem MB155 Fourier transformed spectrophotometer using $\mathrm{KBr}$ pellets. UV-Vis diffused reflectance spectra were taken with a Shimadzu UV2101PC spectrometer equipped with an integral sphere. Barium sulfate was used as the reflectance standard. The size and morphology of the samples were determined by
SEM. Surface areas were measured by physical adsorption of nitrogen at liquid $\mathrm{N}_{2}$ temperature using a volumetric system. The Ti K-edge $\mathrm{X}$-ray absorption spectra were obtained in the transmission mode at the Synchrotron Radiation Research Center in Taiwan. The ion chambers which were used for measuring the incident and transmitted photon intensities were filled with a mixture of nitrogen and argon, and argon gas, respectively. The photon energies were calibrated using the known absorption edge of $\mathrm{Ti}$ foil.

\subsection{Catalytic reactions}

The catalytic activities of the Ti-SAPO molecular sieves in oxidation of various organic compounds were examined using a batch reactor, which composed of a three-neck flask connected with a reflux condenser, a thermometer and a syringe pump for the feed of hydrogen peroxide (32-33\%, Acros Organics). The reaction was operated at $80^{\circ} \mathrm{C}$ under atmospheric pressure. The liquid products were separated with a DP-1 capillary column and detected by a FID detector in a Chrompac CP9000 GC.

\section{Results and discussion}

\subsection{Characteristics of Ti-SAPO}

The Ti/Si-containing aluminophosphate samples prepared in this study were well-crystallized materials. The $\mathrm{AlPO}_{4^{-}}-5$ and VPI-5 structures were confirmed by X-ray diffraction in Fig. 1A and B, respectively. The synthetic condition for Ti/Si-substituted VPI-5 was found to be more critical than that for $\mathrm{AlPO}_{4}-5$. At hydrothermal temperature of $142^{\circ} \mathrm{C}$, which is generally used for synthesis of VPI-5, the hetero-element-substituted products are mainly $\mathrm{AlPO}_{4}-11$ and $\mathrm{AlPO}_{4}-\mathrm{H} 3$ phases instead of VPI5. When the hydrothermal temperature was raised to $148^{\circ} \mathrm{C}$, VPI-5 structure could be obtained reproducibly. However, some of the 


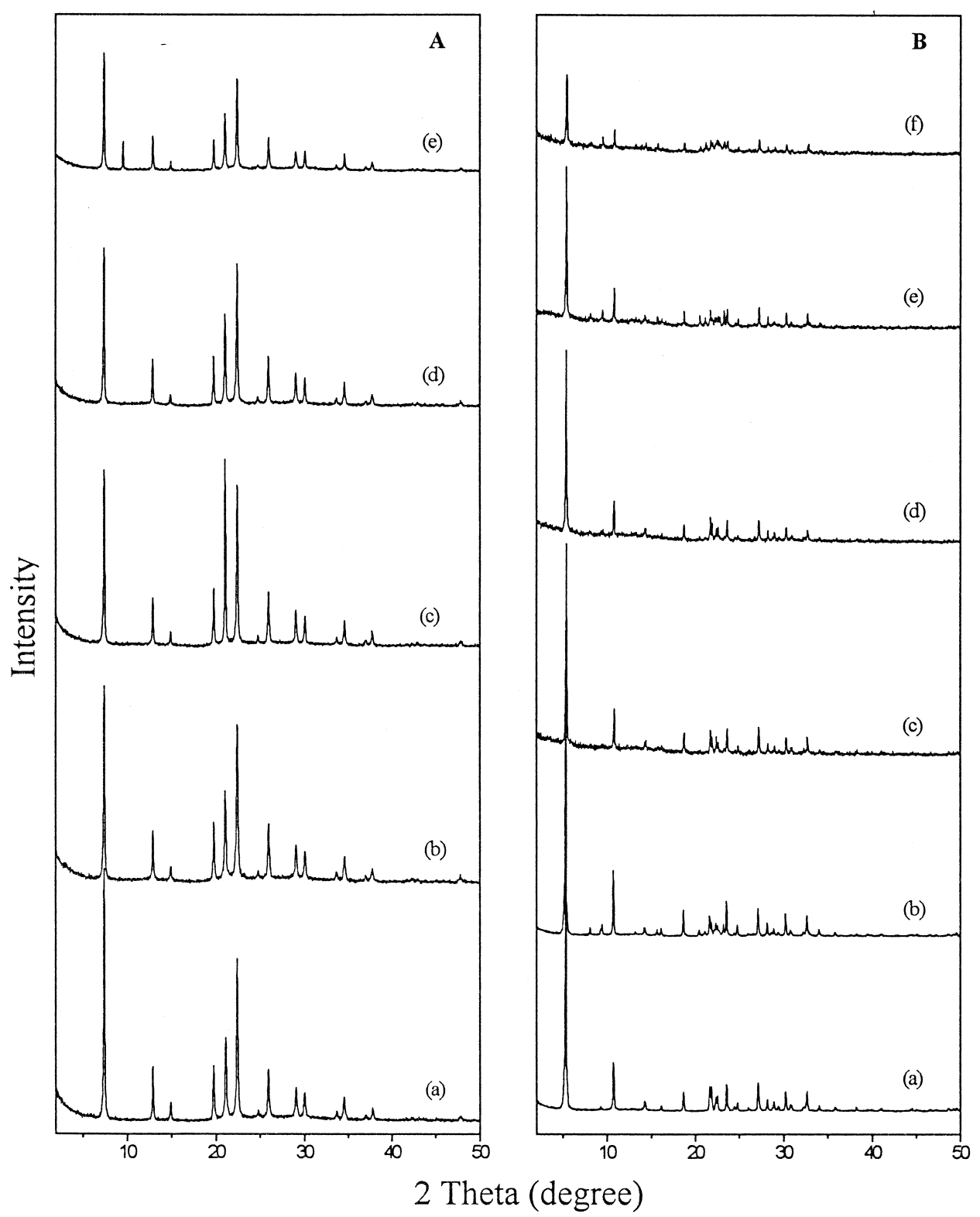

Fig. 1. XRD patterns of (A) $\mathrm{AlPO}_{4}-5$ series: (a) AlPO 4 -5, (b) SAPO-5, (c) 2\% Ti-SAPO-5, (d) 4\% Ti-SAPO-5, (e) 6\% Ti-SAPO-5, and (B) VPI-5 series: (a) VPI-5, (b) Si-VPI-5, (c) $1 \%$ Ti-Si-VPI-5, (d) 2\% Ti-Si-VPI-5, (e) 3\% Ti-Si-VPI-5, (f) 5\% Ti-Si-VPI-5.

products still contained a small amount of $\mathrm{AlPO}_{4}-11$ phase. The as-synthesized VPI-5 contained no organic templates in the channels, and would transform to $\mathrm{AlPO}_{4}-8$ structure when heating at temperatures higher than $80^{\circ} \mathrm{C}$ in air. Fig. 1 shows that the peak intensity of the XRD patterns decreases slightly with Ti content, implying that the incorporation of $\mathrm{Ti}$ into the framework would decrease the crystallinity of the samples. However, obvious shrinkage in the intensity of the XRD peaks is only observed when the $\mathrm{Ti} / \mathrm{Al}$ atomic ratios in the gels were 6 and 5\% for SAPO-5 and Si-VPI-5, respectively. Above this maximum Ti-loadings, the crystalline phases of these two molecular sieves could no longer be reproducibly obtained. 
The amount of $\mathrm{Ti}$ and $\mathrm{Si}$ incorporated into the aluminophosphate molecular sieves was analyzed by ICP-AES and the results are tabulated in Table 1. The $\mathrm{Si}$ contents in the $\mathrm{AlPO}_{4}-5$ series are all close to a $\mathrm{Si} / \mathrm{Al}$ atomic ratio of 0.1 , which is the ratio started in the gels. In contrary, the $\mathrm{Si} / \mathrm{Al}$ ratios in VPI-5 series are apparently lower than that in the gels. Moreover, the Si content decreases markedly with the increase in Ti-loading. On the other hand, the Ti content in the solid products, based on the $\mathrm{Ti} / \mathrm{Al}$ atomic ratio, is proportional to but slightly lower than that added in the gels. The $\mathrm{Ti} / \mathrm{Al}$ ratio of ca. 0.05 is the maximum amount of Ti that can be incorporated into SAPO-5, while ca. 0.04 for Si-VPI-5. These results indicate that the crystalline structure of $\mathrm{AlPO}_{4}-5$ can tolerate greater amount of hetero-element substitution than that of VPI-5. Moreover, since the $\mathrm{P} / \mathrm{Al}$ atomic ratios for hetero-atom-substituted samples are all lower than 1 , the $\mathrm{Si}(\mathrm{IV})$ and Ti(IV) are likely replaced by the phosphorus positions in the framework.

Table 1 also shows that the surface areas retain relatively high up to $\mathrm{Ti} / \mathrm{Al}$ ratios of 0.025 and 0.049 for Si-VPI-5 and SAPO-5, respectively. A marked decrease in surface area however was seen on $\mathrm{Si}-\mathrm{VPI}-5$ with $\mathrm{Ti} / \mathrm{Al}=$ 0.039. In the $\mathrm{AlPO}_{4}-5$ series, the variation of surface areas is less obvious, although samples of higher Ti contents have slightly lower surface areas. These results imply that some amorphous structures probably form on catalysts of high Ti-loading.

SEM photographs shown in Fig. 2 demonstrate that the morphology has little changes for $\mathrm{AlPO}_{4}-5$ series but great changes for VPI-5 series when $\mathrm{Ti}$ is incorporated. Crystallites in rectangle rod shape were observed for $\mathrm{AlPO}_{4}-5$ and all the Ti-SAPO-5 compounds. For Ti/Sisubstituted VPI-5, the morphology changes from crystalline rods of smooth surfaces to rods grafted with small grain particles. Moreover, the grain particles grow larger as the Ti-loading increases. However, neither XRD nor Raman spectroscopy detected any $\mathrm{TiO}_{2}$ phases present in the samples. Since the sizes of the grain particles were in sub-microns to microns, they should be detectable with Raman spectroscopy if they were $\mathrm{TiO}_{2}$ particles. Therefore, the grain particles should still be the VPI-5 structure instead of $\mathrm{TiO}_{2}$. Similar morphological changes were observed on MeVPI-5 [26]. The surface defects were considered to serve as seeds for the

Table 1

Sample composition and surface area

\begin{tabular}{|c|c|c|c|c|c|c|c|c|c|}
\hline \multirow[t]{3}{*}{ Catalyst } & \multicolumn{8}{|c|}{ Atomic ratio } & \multirow{3}{*}{$\begin{array}{l}\text { Surface area } \\
\left(\mathrm{m}^{2} \mathrm{~g}^{-1}\right)\end{array}$} \\
\hline & \multicolumn{4}{|c|}{ Gel } & \multicolumn{4}{|c|}{ Product $^{\mathrm{a}}$} & \\
\hline & $\mathrm{Ti}$ & $\mathrm{Si}$ & $\mathrm{P}$ & $\mathrm{Al}$ & $\mathrm{Ti}$ & $\mathrm{Si}$ & $\mathrm{P}$ & $\mathrm{Al}$ & \\
\hline Si-VPI-5 & 0 & 0.1 & 1.0 & 1.0 & 0 & 0.083 & 0.95 & 1.00 & 283 \\
\hline $1 \% \mathrm{Ti}-\mathrm{Si}-\mathrm{VPI}-5$ & 0.01 & 0.1 & 1.0 & 1.0 & 0.0076 & 0.062 & 0.96 & 1.00 & 256 \\
\hline $5 \% \mathrm{Ti}-\mathrm{Si}-\mathrm{VPI}-5$ & 0.05 & 0.1 & 1.0 & 1.0 & 0.039 & 0.057 & 0.95 & 1.00 & 76 \\
\hline $\mathrm{AlPO}_{4}-5$ & 0 & 0 & 1.0 & 1.0 & 0 & 0 & 1.01 & 1.00 & 243 \\
\hline SAPO-5 & 0 & 0.1 & 1.0 & 1.0 & 0 & 0.092 & 0.94 & 1.00 & 278 \\
\hline $2 \%$ Ti-SAPO-5 & 0.02 & 0.1 & 1.0 & 1.0 & 0.019 & 0.088 & 0.94 & 1.00 & 254 \\
\hline 4\% Ti-SAPO-5 & 0.04 & 0.1 & 1.0 & 1.0 & 0.034 & 0.094 & 0.94 & 1.00 & 208 \\
\hline 6\% Ti-SAPO-5 & 0.06 & 0.1 & 1.0 & 1.0 & 0.049 & 0.103 & 0.92 & 1.00 & 198 \\
\hline
\end{tabular}

${ }^{\mathrm{a}}$ From ICP-AES elemental analysis. 
growth of the smaller crystallites grafted on the large crystal surfaces. These results again imply that the process of crystal growth for VPI-5 is much more sensitive than that for $\mathrm{AlPO}_{4}-5$.
The UV-Vis spectra of Ti-substituted SAPO molecular sieves are shown in Fig. 3. The peak at ca. $225 \mathrm{~nm}$ is usually assigned to charge transfer from $\mathrm{O}^{2-}$ to $\mathrm{Ti}^{4+}$ and is observed on
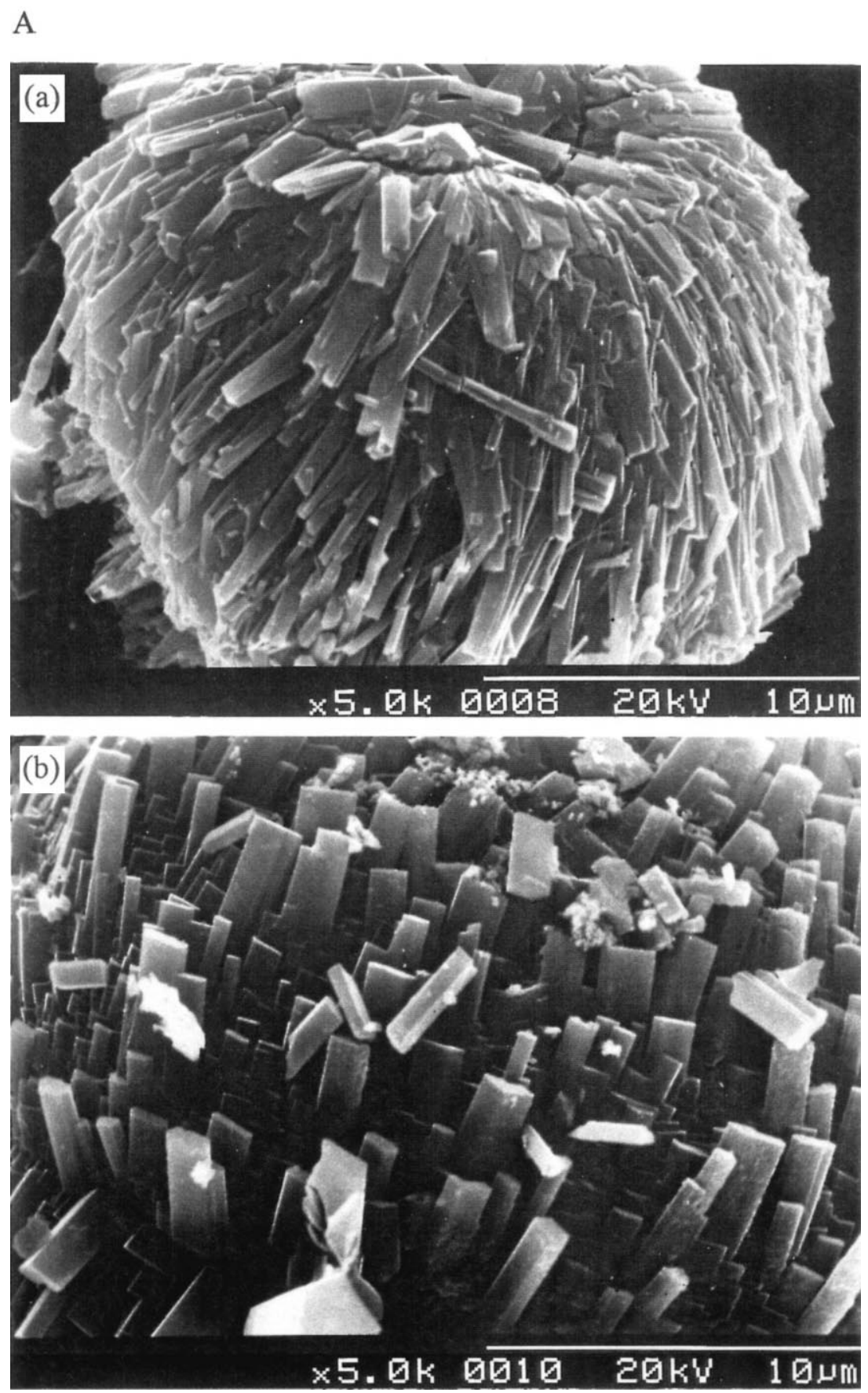

Fig. 2. SEM photographs of (A) $\mathrm{AlPO}_{4}-5$ series: (a) $\mathrm{AlPO}_{4}-5$, (b) $2 \%$ Ti-SAPO-5, (c) 4\% Ti-SAPO-5, (d) 6\% Ti-SAPO-5, and (B) VPI-5 series: (a) VPI-5, (b) 1\% Ti-Si-VPI-5, (c) $2 \%$ Ti-Si-VPI-5, (d) 3\% Ti-Si-VPI-5, (e) 5\% Ti-Si-VPI-5. 
A
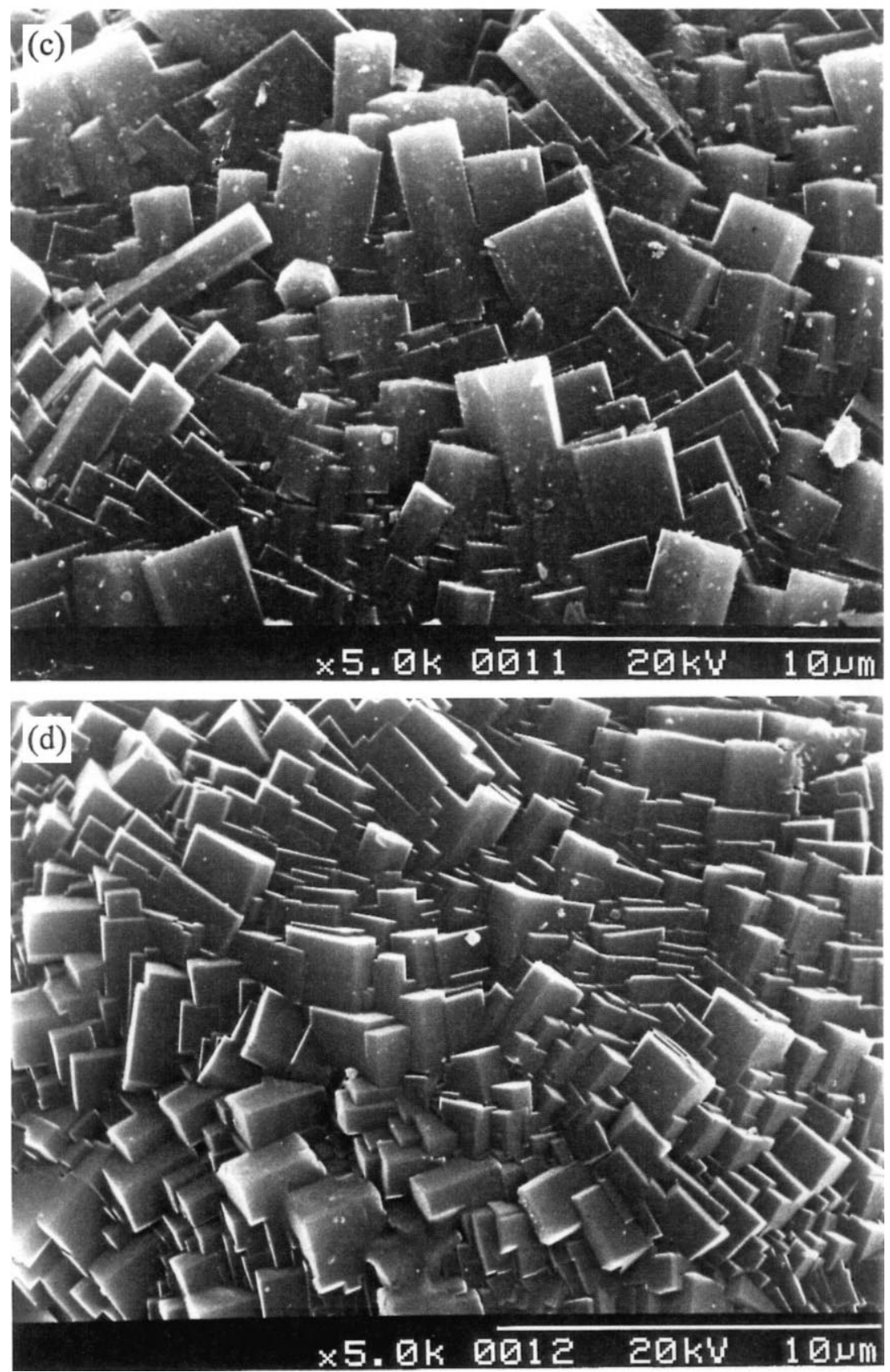

Fig. 2 (continued).

all the spectra of oxide samples containing Ti. However, pristine aluminophosphate has an absorption around $220 \mathrm{~nm}$, which is partially overlapping with the $\mathrm{O}-\mathrm{Ti}$ charge transfer band.
The other band at $250-330 \mathrm{~nm}$ is attributed to electron transfer from the valence band to the conduction band of $\mathrm{TiO}_{2}$. The intensity and width of this band were found to increase with 
B
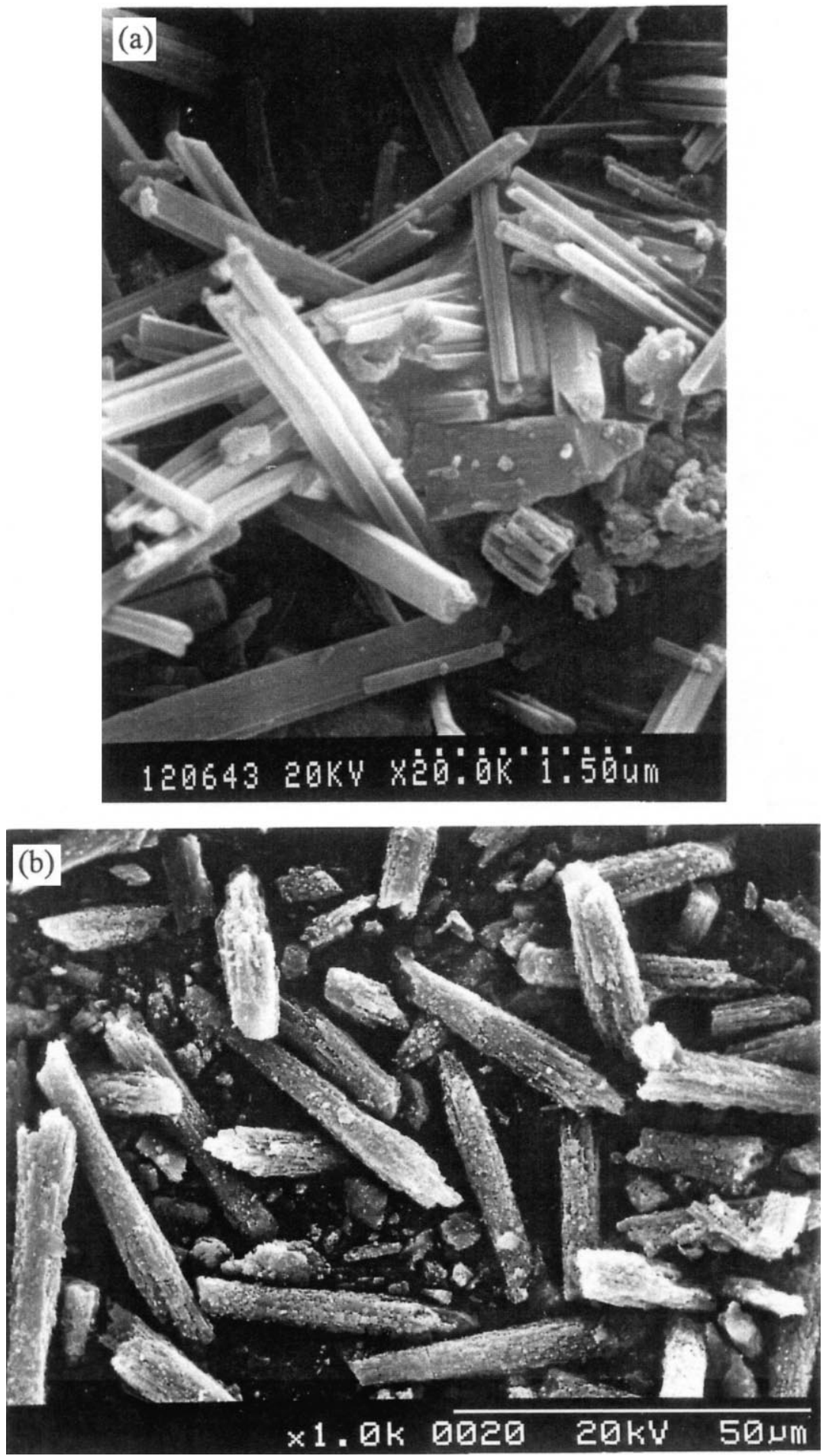

Fig. 2 (continued). 

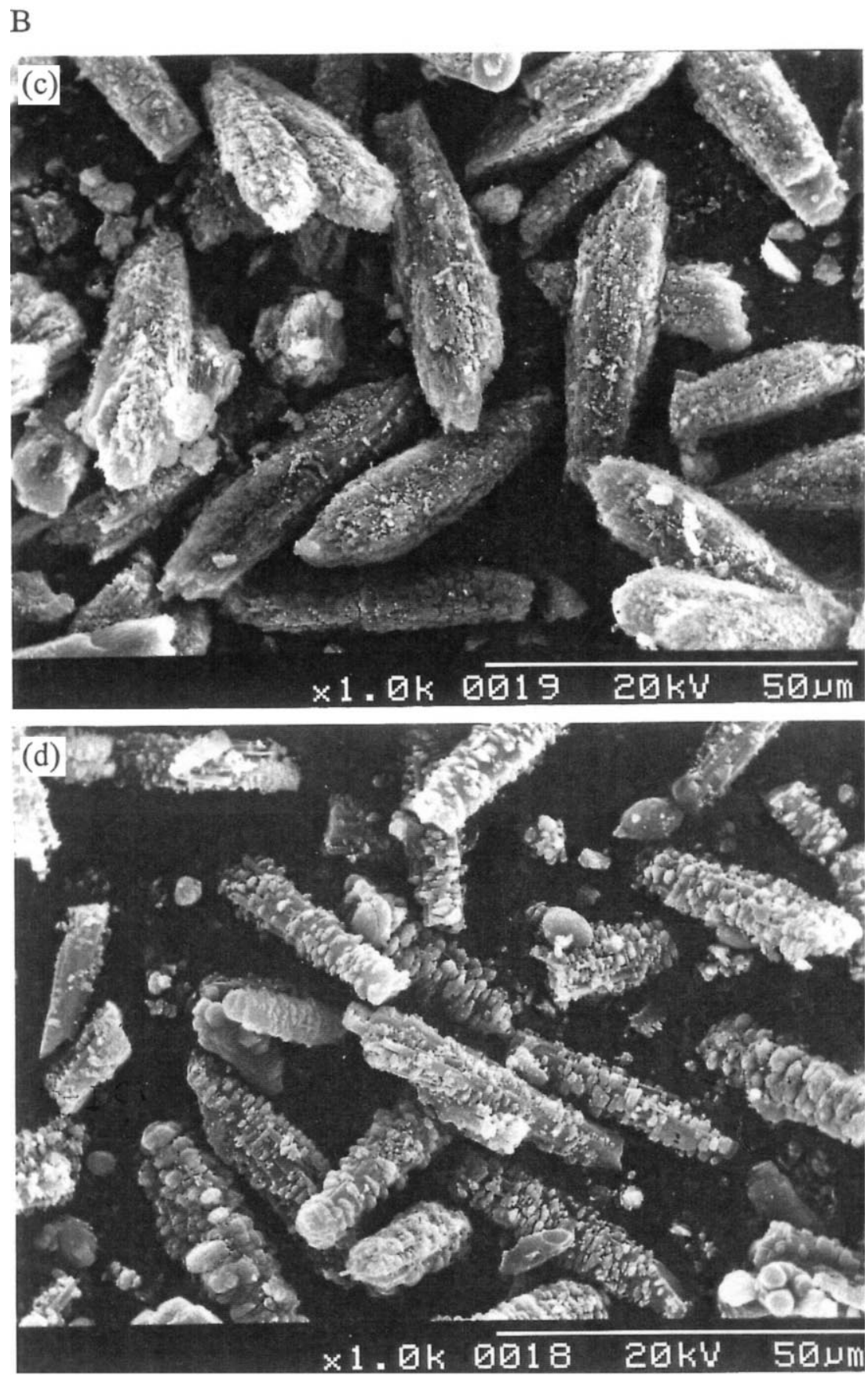

Fig. 2 (continued).

Ti-loading. These results indicate that the formation of extra framework $\mathrm{TiO}_{2}$ crystallites in the SAPO samples cannot be excluded. The partial blockage of the pores by tiny $\mathrm{TiO}_{2}$ particles probably also accounts for the lower surface area of Ti-SAPO samples of higher Ti- 


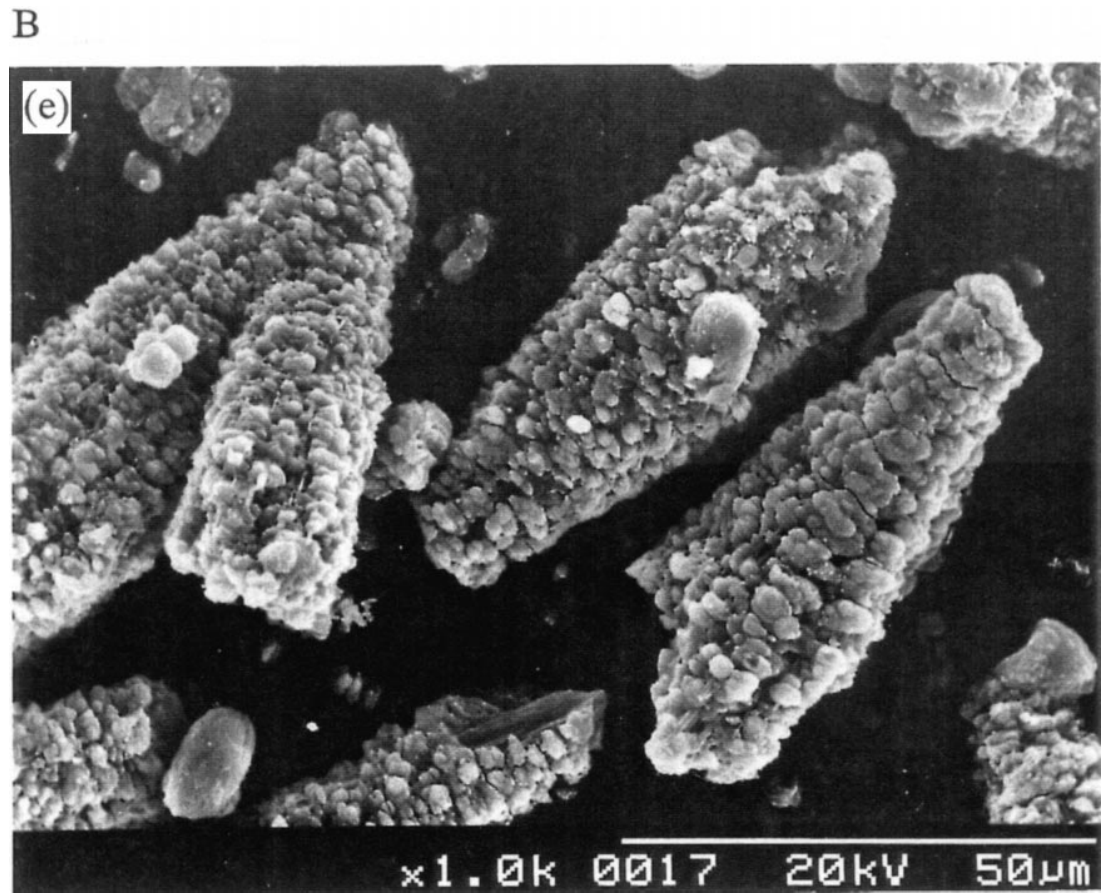

Fig. 2 (continued).

loadings. Nevertheless, the size of the $\mathrm{TiO}_{2}$ particles must be too tiny to be detected by Raman spectroscopy.

Fig. 4 shows the IR spectra of Ti-substituted SAPO samples in the framework vibration region. Although both kinds of molecular sieves have absorption appear in a similar region, the VPI-5 structure gives better resolved peaks than $\mathrm{AlPO}_{4}-5$. Hence, the changes in spectra as a function of Ti-loading are more obvious for the VPI-5 series than for the $\mathrm{AlPO}_{4}-5$ series. As the Ti-loading increases, the absorption bands become broader for both molecular sieve structures, implying a decrease in crystallinity. That is consistent with the XRD results. The main peaks at 1050 and $1170 \mathrm{~cm}^{-1}$ in the IR spectra of VPI-5 remained well-resolved when only $\mathrm{Si}$ was incorporated, but they merged to become one broad band when Ti is also introduced. The Ti-substituted SAPO-5 structure of high Si-loading was synthesized by Tuel and Taarit [25] with different methods. They observed an IR absorption around $970 \mathrm{~cm}^{-1}$ on their calcined samples. Although there are still arguments about the assignment of this peak, it is generally considered to correspond to $\mathrm{Si}-\mathrm{O}-\mathrm{Ti}$ stretching vibration. In our case, however, the $970 \mathrm{~cm}^{-1}$ peak was only observed on the $5 \% \mathrm{Ti}-\mathrm{Si}-\mathrm{VPI}-5$ sample, which has a very distorted structure and low surface area. Therefore, the IR spectra of our samples contribute no diagnostic information about whether $\mathrm{Ti}$ is incorporated in the aluminophosphate framework or not.

Fig. 5 shows the Ti K-edge X-ray absorption near-edge structure (XANES) spectra of Ti-substituted SAPO compounds. For comparison, the XANES spectrum of anatase $\mathrm{TiO}_{2}$ is also displayed in Fig. 5. As indicated in Fig. 5(a), the spectrum of anatase $\mathrm{TiO}_{2}$ shows three weak peaks at 4968, 4970 and $4973 \mathrm{eV}$ in the nearedge region. These peaks are assigned to $1 \mathrm{~s} \rightarrow$ $3 \mathrm{~d}$ transition, which is Laporte forbidden in the octahedral coordination [27]. Before degassing, the Ti-SAPO-5 samples also show three peaks in the near-edge region. However, the peaks shift toward higher energy and the intensity of 


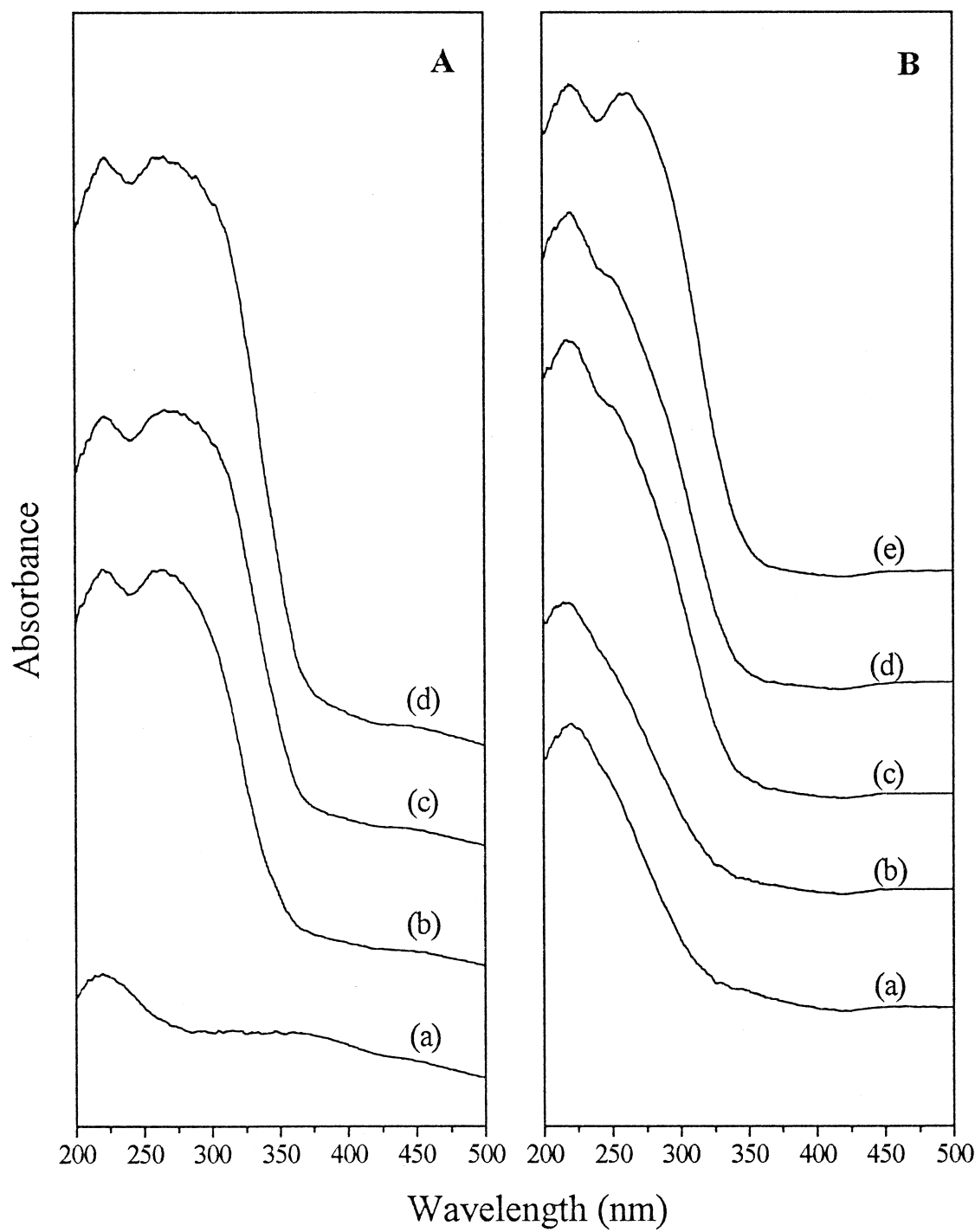

Fig. 3. Diffuse reflectance UV-Vis spectra of (A) AlPO 4 -5 series: (a) AlPO 4 -5, (b) 2\% Ti-SAPO-5, (c) 4\% Ti-SAPO-5, (d) 6\% Ti-SAPO-5, and (B) VPI-5 series: (a) VPI-5, (b) Si-VPI-5, (c) $1 \%$ Ti-Si-VPI-5, (d) $2 \%$ Ti-Si-VPI-5, (e) 5\% Ti-Si-VPI-5.

the $4972 \mathrm{eV}$ peak is stronger than that of the other two. For the degassed samples, only the $4972 \mathrm{eV}$ peak is retained. The $4972 \mathrm{eV}$ peak of relatively strong intensity is assigned to $1 \mathrm{~s} \rightarrow 3 \mathrm{~d}$ transition of tetrahedral $\mathrm{Ti}$, in which the transition is Laporte allowed. The change in spectral patterns was found to be reversible when the degassed sample was rehydrated. Although detailed analysis of the extended X-ray absorption fine structure (EXAFS) is impossible due to the low Ti-loading in the samples, these results reveal that most of $\mathrm{Ti}$ in Ti-SAPO of low Ti-loadings is incorporated in the framework of the molecular sieves. The samples without degassing contain $\mathrm{Ti}$ of both tetrahedral and octahedral coordinations, and the coordination environment of $\mathrm{Ti}$ varies with the extent of hydration. If the Ti(IV) incorporated in SAPO can 


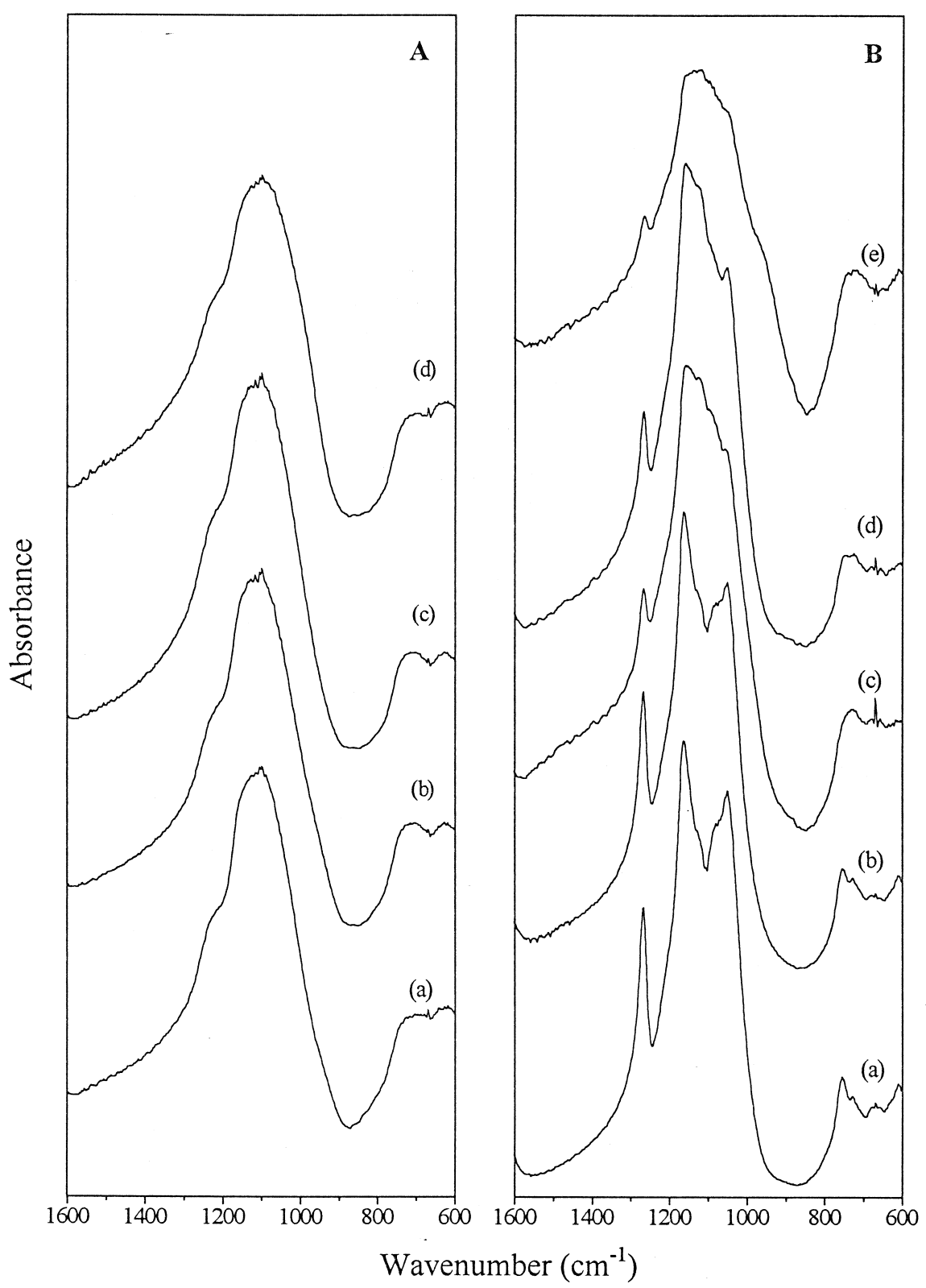

Fig. 4. FT-IR spectra in framework vibration region of (A) $\mathrm{AlPO}_{4}-5$ series: (a) $\mathrm{AlPO}_{4}-5$, (b) $2 \%$ Ti-SAPO-5, (c) 4\% Ti-SAPO-5, (d) $6 \%$ Ti-SAPO-5, and (B) VPI-5 series: (a) VPI-5, (b) Si-VPI-5, (c) 1\% Ti-Si-VPI-5, (d) $2 \%$ Ti-Si-VPI-5, (e) 5\% Ti-Si-VPI-5.

bond with water molecules reversibly, it should be able to serve as a catalytic center for coordination with reactants.

\subsection{Catalytic properties of Ti-SAPOs}

The catalytic behaviors of Ti-SAPO molecular sieves were studied in the oxidation of sev- eral organic compounds using hydrogen peroxide as the oxidant. Table 2 shows that Ti-SAPOs have very low activities in the oxidation of alkenes. The activities were slightly higher for alkenes with hydroxyl or amino functional groups. It suggests that the organic substrates are hard to approach and be adsorbed on the hydrophilic surfaces of aluminophosphate mole- 


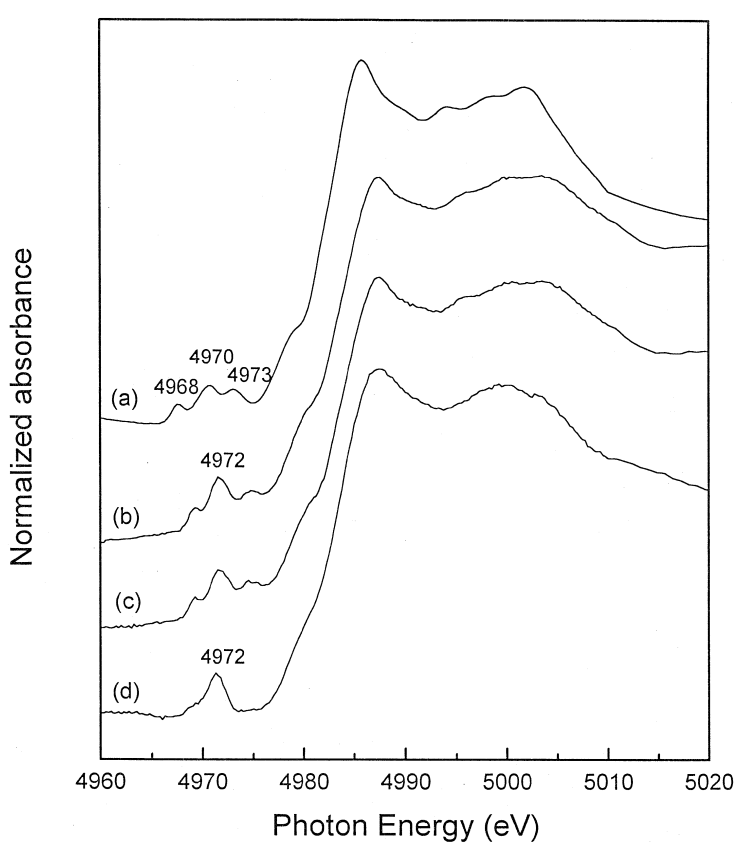

Fig. 5. Ti K-edge X-ray absorption spectra of (a) anatase $\mathrm{TiO}_{2}$, (b) $2 \% \mathrm{Ti}-\mathrm{SAPO}-5$, (c) $4 \% \mathrm{Ti}-\mathrm{SAPO}-5$, (d) $2 \% \mathrm{Ti}-\mathrm{SAPO}-5$ after degassing under 0.1 Torr for $3 \mathrm{~h}$.

cular sieves. Instead, the surface should be covered up by water or $\mathrm{H}_{2} \mathrm{O}_{2}$ molecules. The adsorption is improved when polar functional groups are attached to the reactants. The catalytic activity was further enhanced when phenol was the reactant (Table 3). The main products were catechol (CAT) and hydroquinone (HQ). In addition, the procedure of adding $\mathrm{H}_{2} \mathrm{O}_{2}$ was found critical. Adding $\mathrm{H}_{2} \mathrm{O}_{2}$ dropwise to the mixture of organic reactants and catalyst heated at reaction temperature gives better phenol conversion than mixing $\mathrm{H}_{2} \mathrm{O}_{2}$ and the substrates beforehand.

\subsection{Phenol hydroxylation}

The influence of solvents on phenol hydroxylation is shown in Table 3. Without adding other solvents, the water present in $33 \% \mathrm{H}_{2} \mathrm{O}_{2}$ solution serves as the solvent. The phenol conversion reaches $12.3 \%$ and the selectivities of CAT and HQ are $67 \%$. When other solvents were added with the phenol/solvent molar ratios kept at 1:2, phenol conversion was found to vary markedly with the polarity of the solvents. The phenol conversion increases in the order of water $\sim$ methanol $<\mathrm{THF} \ll$ acetone, while the dielectric constant of the solvents decreases in the order of water $(80.2)>$ methanol $(32.7)>$ acetone (20.7) $>$ THF (7.6). In other words, the solvents of mild polarity give the optimal activity. The low conversions of phenol in solvents of high polarity such as water and methanol are attributed to that the solvent molecules are preferred to phenol in covering up the hydrophilic surfaces of the catalyst. Consequently, the proceeding of reaction is impeded. However, a solvent of low polarity such as THF is not favored either. It is probably due to polar prod-

Table 2

The catalytic activities of Ti-SAPOs in oxidation of alkenes with $\mathrm{H}_{2} \mathrm{O}_{2}$ Catalyst $=0.2 \mathrm{~g}$; Molar ratio of $\mathrm{H}_{2} \mathrm{O}_{2}$ :organic substrate:solvent $=1: 1: 1$; Reaction period $=6 \mathrm{~h}$.

\begin{tabular}{llll}
\hline Catalyst & Solvent $/$ temperature & Reactant & Conversion $(\%)^{\mathrm{a}}$ \\
\hline $1 \%$ Ti-SAPO-5 & acetone $/ 60^{\circ} \mathrm{C}$ & $1-$ Hexene & $\sim 1$ \\
$2 \%$ Ti-SAPO-5 & acetone $/ 60^{\circ} \mathrm{C}$ & $1-$ Hexene & $\sim 1$ \\
$2 \%$ Ti-Si-VPI-5 & acetone $/ 60^{\circ} \mathrm{C}$ & $1-$ Hexene & $\sim 1$ \\
$2 \%$ Ti-SAPO-5 & THF $/ 65^{\circ} \mathrm{C}$ & $1-$ Hexene & $\sim 2$ \\
$2 \%$ Ti-SAPO-5 & acetone $/ 60^{\circ} \mathrm{C}$ & Allyl alcohol & 3.3 \\
$2 \%$ Ti-SAPO-5 & THF $/ 70^{\circ} \mathrm{C}$ & Allyl alcohol & 5.3 \\
$2 \%$ Ti-SAPO-5 & ethanol $/ 80^{\circ} \mathrm{C}$ & Allyl alcohol & 7.0 \\
$2 \%$ Ti-SAPO-5 & THF $/ 70^{\circ} \mathrm{C}$ & Allyl amine & 2.5 \\
$2 \%$ Ti-SAPO-5 & THF $/ 70^{\circ} \mathrm{C}$ & Diallyl amine & 6.8 \\
$2 \%$ Ti-SAPO-5 & THF $/ 70^{\circ} \mathrm{C}$ & Triallyl amine & 1.8 \\
\hline
\end{tabular}

\footnotetext{
${ }^{\mathrm{a}}$ The data relative deviation $\sim 10 \%$.
} 
Table 3

Effect of solvent on hydroxylation of phenol

Catalyst $=0.2 \mathrm{~g} 2 \%$ Ti-SAPO-5, $\mathrm{H}_{2} \mathrm{O}_{2}$ :phenol $=1: 1$ (molar ratio), reaction temperature $=80^{\circ} \mathrm{C}$, reaction period $=6 \mathrm{~h}$.

\begin{tabular}{|c|c|c|c|c|c|c|}
\hline \multirow[t]{2}{*}{ Solvent } & \multirow{2}{*}{$\begin{array}{l}\text { Phenol:solvent:water } \\
\text { (molar ratio) }\end{array}$} & \multirow{2}{*}{$\begin{array}{l}\text { Phenol } \\
\text { conversion }(\%)\end{array}$} & \multicolumn{2}{|c|}{ Yield $(\%)$} & \multirow{2}{*}{$\begin{array}{l}\text { Selectivity of } \\
\text { HQ + CAT }(\%)\end{array}$} & \multirow[t]{2}{*}{$\mathrm{CAT} / \mathrm{HQ}$} \\
\hline & & & $\overline{\mathrm{CAT}}$ & $\overline{\mathrm{HQ}}$ & & \\
\hline- & $1: 0: 3.7$ & 12.3 & 6.2 & 2.1 & 67 & 2.95 \\
\hline Water & $1: 2: 3.7$ & 7.8 & 3.7 & 1.2 & 63 & 3.08 \\
\hline Methanol & $1: 2: 3.7$ & 6.6 & 4.1 & 2.2 & 95 & 1.86 \\
\hline THF & $1: 2: 3.7$ & 9.2 & 4.8 & 3.1 & 86 & 1.55 \\
\hline Acetone & $1: 2: 3.7$ & 17.3 & 9.3 & 7.2 & 95 & 1.29 \\
\hline Acetone & $1: 5: 3.7$ & 10.6 & 5.1 & 4.2 & 88 & 1.21 \\
\hline Acetone & $1: 1: 3.7$ & 22.4 & 10.1 & 7.5 & 79 & 1.35 \\
\hline Acetone & $1: 0.5: 3.7$ & 29.7 & 16.4 & 10.6 & 91 & 1.55 \\
\hline Acetone & $1: 0.2: 3.7$ & 37.6 & 21.1 & 14.3 & 94 & 1.48 \\
\hline
\end{tabular}

${ }^{\mathrm{a}}$ Water from $33 \% \mathrm{H}_{2} \mathrm{O}_{2}$ solution.

ucts formed on the catalyst surface that cannot be efficiently removed by the solvents of low polarity.

Table 3 also shows that the solvents of high polarity can induce polar products. The molar ratios of CAT to HQ are higher in water and methanol but lower for THF and acetone. That is, another evidence that the solvent plays an important role in removing the products away from the catalyst surfaces.

Another factor that affects phenol conversion is the phenol-to-solvent ratio, as shown in Table 3 . When larger amount of acetone is used, the conversion becomes lower. In addition, some low molecular weight products were observed from GC analysis when large amount of acetone was used as solvent. It suggests that acetone may react with $\mathrm{H}_{2} \mathrm{O}_{2}$ and consume a portion of $\mathrm{H}_{2} \mathrm{O}_{2}$ in addition to the dilution of the reactants. Therefore, a large amount of acetone is not preferred. The highest conversion is achieved when phenol/acetone ratio is ca. 1:0.2, and this optimum concentration was used for the catalytic studies hereafter.

The effect of the molar ratio of the reactants is shown in Table 4. The phenol conversion increases from ca. 38 to $55 \%$ when $\mathrm{H}_{2} \mathrm{O}_{2}$ /phenol molar ratio increases from 1 to 3 . Then the conversion retains around 55\% and is independent of the increase in $\mathrm{H}_{2} \mathrm{O}_{2}$ quantity. The plateau is caused by water concentration in- creases with $\mathrm{H}_{2} \mathrm{O}_{2}$ /phenol ratio and the competitive adsorption of $\mathrm{H}_{2} \mathrm{O}$ molecules on the active sites reduces the effect of increase in $\mathrm{H}_{2} \mathrm{O}_{2}$ concentration.

The influence of $\mathrm{Ti}$ content and different crystalline structure of molecular sieves on the catalytic activity is demonstrated in Table 5. Both pure aluminophosphate and SAPO molecular sieves gave low activities in phenol hydroxylation, but the conversion is obviously improved when $\mathrm{Ti}$ is incorporated in the molecular sieves. For both Ti-SAPO-5 and Ti-Si-VPI-5, the phenol conversion reaches a maximum and then decreases with the increase in Ti content. It is attributed that a portion of Ti probably forms extra framework $\mathrm{TiO}_{2}$ when the Ti-loading is high. These $\mathrm{TiO}_{2}$ crystallites would catalyze the decomposition of $\mathrm{H}_{2} \mathrm{O}_{2}$ to $\mathrm{H}_{2} \mathrm{O}$ and $\mathrm{O}_{2}$, and decrease the effective $\mathrm{H}_{2} \mathrm{O}_{2}$ concentration for

Table 4

Effect of reactant concentration on the hydroxylation of phenol

Catalyst $=0.2 \mathrm{~g} 2 \%$ Ti-SAPO-5, phenol:acetone: water $=1: 0.2: 3.7$ (molar ratio), reaction temperature $=80^{\circ} \mathrm{C}$, reaction period $=6 \mathrm{~h}$.

\begin{tabular}{|c|c|}
\hline $\begin{array}{l}\mathrm{H}_{2} \mathrm{O}_{2} \text { /phenol } \\
\text { (equivalent ratio) }\end{array}$ & $\begin{array}{l}\text { Phenol } \\
\text { conversion (\%) }\end{array}$ \\
\hline 1 & 37.6 \\
\hline 2 & 50.2 \\
\hline 3 & 55.7 \\
\hline 5 & 54.2 \\
\hline 10 & 56.1 \\
\hline
\end{tabular}


Table 5

Effect of Ti content and crystalline structure of Ti-Si-AlPO molecular sieves on the hydroxylation of phenol

Catalyst $=0.2 \mathrm{~g}$, phenol $=2.5 \mathrm{~g}$, reaction temperature $=80^{\circ} \mathrm{C}$, reaction period $=6 \mathrm{~h}$, molar ratio of phenol: $\mathrm{H}_{2} \mathrm{O}_{2}:$ acetone: $\mathrm{water}=$ $1: 1: 0.2: 3.7$.

\begin{tabular}{|c|c|c|c|c|c|}
\hline \multirow[t]{2}{*}{ Catalyst } & \multirow{2}{*}{$\begin{array}{l}\text { Phenol } \\
\text { conversion }(\%)\end{array}$} & \multicolumn{2}{|c|}{ Yield $(\%)$} & \multirow{2}{*}{$\begin{array}{l}\text { Selectivity of } \\
\text { CAT + HQ }(\%)\end{array}$} & \multirow{2}{*}{$\begin{array}{l}\mathrm{CAT} / \mathrm{HQ} \\
\text { (molar ratio) }\end{array}$} \\
\hline & & $\overline{\mathrm{CAT}}$ & $\overline{\mathrm{HQ}}$ & & \\
\hline Blank & 4.7 & 1.6 & - & 34 & - \\
\hline Si-VPI-5 & 9.7 & 4.1 & 2.1 & 64 & 1.95 \\
\hline $1 \% \mathrm{Ti}-\mathrm{Si}-\mathrm{VPI}-5$ & 28.7 & 17.4 & 10.8 & 98 & 1.61 \\
\hline $2 \%$ Ti-Si-VPI-5 & 33.9 & 20.0 & 12.8 & 97 & 1.56 \\
\hline $\mathrm{AlPO}_{4}-5$ & 7.6 & 3.2 & 1.9 & 67 & 1.68 \\
\hline SAPO-5 & 11.2 & 4.3 & 2.7 & 63 & 1.59 \\
\hline $2 \%$ Ti-SAPO- 5 & 37.6 & 19.7 & 13.0 & 87 & 1.52 \\
\hline $4 \%$ Ti-SAPO-5 & 39.2 & 21.1 & 14.3 & 90 & 1.48 \\
\hline $6 \%$ Ti-SAPO-5 & 34.1 & 18.1 & 11.8 & 88 & 1.53 \\
\hline
\end{tabular}

${ }^{\mathrm{a}}$ The Ti-SAPO-5 catalyst without calcination to retain the templates in the pores.

phenol oxidation. Besides, under this optimal reaction condition for Ti-SAPO catalysts, the phenol conversion over TS-1 is lower than those of Ti-SAPO catalysts. The selectivities of the hydroxylation products, CAT and HQ, over TS-1 are also significantly different from that over Ti-SAPO molecular sieves. The polar product, CAT, is preferred to the less polar product, HQ, over Ti-SAPO catalysts, while the product ratio is around 1 over the hydrophobic TS-1.

The crystallinity of the molecular sieves is important for catalytic reactions. The 5\% Ti-SiVPI-5 catalyst of poor crystallinity and low surface area gives only half of the phenol conversion in comparison with those over wellcrystallized samples. Nevertheless, the catalytic activity has no correlation with the pore size. The two aluminophosphate structures under investigation are $\mathrm{AlPO}_{4}-5$ containing pores of 0.73 $\mathrm{nm}$ diameter and VPI-5 containing pores of 1.21 $\mathrm{nm}$ diameter. The phenol conversions over TiSAPO-5 of different Ti-loadings fall in the range around 34-39\%, and that over Ti-Si-VPI-5 varies from 28 to $34 \%$ (without considering the poor-crystallized 5\% Ti-Si-VPI-5). Since VPI-5 has larger pore diameter than $\mathrm{AlPO}_{4}-5$, these results suggest that the internal surfaces of the aluminophosphate molecular sieves probably are not involved in the catalytic reactions. This proposal was affirmed by using one of the uncalcined Ti-SAPO-5 samples with template molecules still in the pores as the catalyst. Similar activity and product selectivity were found as those of the calcined sample.

That the catalytic reactions merely proceed on the external surfaces of the Ti-SAPO molecular sieves is different from those observed over TS-1. Tuel et al. [28] proposed that external surfaces of TS-1 are responsible for CAT formation and the internal channels for HQ formation. Two main reasons may account for the internal surfaces of aluminophosphates having little contribution to the catalytic reactions. First, the one-dimensional channels of $\mathrm{AlPO}_{4}$ molecular sieves limit the interdiffusion of the solvent and the reactant molecules. Second, the pores of $\mathrm{AlPO}_{4}$ molecular sieves are probably tightly filled with water or other polar molecules. In contrast, over TS-1 of pentasil zeolite structure, polar molecules are relatively easy to diffuse in and out through the inter-connected channels. Besides, the interactions between the solvent molecules and the silica walls are weaker than that on aluminophosphate. 
Two explanations may account for the TiSAPO-5 catalysts having slightly higher activities in phenol hydroxylation than Ti-Si-VPI-5. First, the actual amount of $\mathrm{Ti}$ incorporated in the framework of SAPO-5 is higher than that on Si-VPI-5 when well-crystallized structures are concerned. Second, the structure of the pore mouth may be important in anchoring the reactants and facilitating the hydroxylation reaction to proceed.

The typical course of the hydroxylation reaction as a function of reaction period is shown in Fig. 6. In the first hour of the reaction, parabenzoquinone (PBQ) was detected as the only product formed in the solution. The amount of PBQ formed reaches a maximum after $2 \mathrm{~h}$, then decreases and disappears completely after ca. 4 h. CAT appears after $1.5 \mathrm{~h}$, while HQ appears even later, after ca. $2 \mathrm{~h}$. Both CAT and HQ yields increase with further progress of the reaction, and the increments slow down after about $6 \mathrm{~h}$. The presence of PBQ in the early stage of the reaction was also observed by several authors [29-31] over titanium silicalites. Allian et al. [32] suggested that PBQ was a reaction intermediate and it might act as an autocatalyst or an intermediate and cause the oxidation of $\mathrm{H}_{2} \mathrm{O}_{2}$ to $\mathrm{O}_{2}$ and reduction of PBQ to HQ. Since HQ appears almost the moment PBQ yield started to decrease, this proposal may also be applied to our system. However, the observation

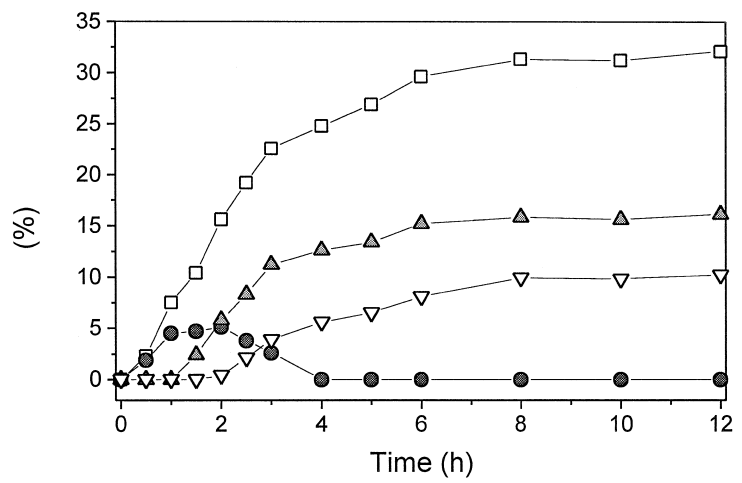

Fig. 6. Phenol conversion and product distribution as a function of reaction period over $2 \%$ Ti-SAPO-5 catalyst; $(\square)$ phenol conversion, $(\boldsymbol{\Delta})$ yield of CAT, $(\nabla)$ yield of $\mathrm{HQ}$, and $(O)$ yield of PBQ. of dark polymeric species since the beginning of the reaction implies that another mechanism, in which PBQ is the over-oxidized product of HQ and an intermediate in the formation of tar [31,33], cannot be excluded. A detailed study on the reaction mechanism is undergoing in our laboratory.

\section{Conclusions}

The $\mathrm{Ti} / \mathrm{Si}$-substituted aluminophosphate molecular sieves of $\mathrm{AlPO}_{4}-5$ and VPI-5 crystal structures were synthesized successfully through hydrothermal methods. As the $\mathrm{Si} / \mathrm{Al}$ atomic ratio in the synthesis gel was kept around $10 \%$, the resultant samples retained the hydrophilic character of aluminophosphate. The crystalline structure of $\mathrm{AlPO}_{4}-5$ can tolerate greater substitution of hetero-element than that of VPI-5. The surface area of Ti-Si-VPI-5 was found to decrease with Ti-loading, but the change is less obvious for Ti-SAPO-5. The incorporation of Ti(IV) on the framework of SAPO was confirmed by the Ti K-edge X-ray absorption spectra. The Ti(IV) centers transformed from octahedral to tetrahedral coordination after the samples were dehydrated.

Because of the hydrophilic nature of the synthesized Ti-SAPO molecular sieves, they have low catalytic activities in the oxidation of organic substrates of low polarity using hydrogen peroxide as the oxidant. On the contrary, this material catalyzes the hydroxylation of phenol to CAT and HQ efficiently, especially under the condition of slow addition of $\mathrm{H}_{2} \mathrm{O}_{2}$. The conversion of phenol and the selectivities of CAT and HQ were found to be affected by the polarity of the solvent, the crystalline structure of aluminophosphate and the $\mathrm{Ti}$ content. Solvents of medium polarity such as acetone are preferred because they can efficiently transfer the reactants to and products away from the catalyst surfaces. The CAT/HQ molar ratios in products are always higher with Ti-SAPOs as the catalysts than with TS-1, probably because the 
hydrophilic surface of aluminophosphate stabilizes the polar product, CAT.

Ti-substituted SAPO-5 molecular sieves show higher catalytic activities than Ti-Si-VPI-5, although the latter has a larger pore diameter than the former. Besides, similar catalytic activities were observed on Ti-SAPO-5 with and without templating molecules. Therefore, phenol hydroxylation reaction is considered to proceed mainly on the external surfaces of the $\mathrm{AlPO}_{4}$ catalysts. The internal surfaces of the particles have little contribution to the catalytic reactions due to the fill-up of the pore volume by the polar molecules present in the solutions.

\section{Acknowledgements}

Financial support from the National Science Council of Taiwan, Republic of China and the free supply of pseudoboehmite from CONDEA Vista, USA are gratefully acknowledged.

\section{References}

[1] S.T. Wilson, B.M. Lok, E.M. Flanigen, US Patent 4310440, 1982.

[2] S.T. Wilson, B.M. Lok, C.A. Messina, T.R. Cannan, E.M. Flanigen, J. Am. Chem. Soc. 104 (1982) 1146.

[3] B.M. Lok, C.A. Messina, R.L. Patton, T.R. Cannan, E.M. Flanigen, J. Am. Chem. Soc. 106 (1984) 6092.

[4] W.M. Meier, D.H. Olson, C.H. Bearlocher, Zeolites 17 (1996) A1.

[5] E.M. Flanigen, R.L. Patton, S.T. Wilson, in: P.J. Grobet, et al. (Eds.), Innovation in Zeolite Materials Science, Elsevier, Amsterdam, 1987, p. 13.

[6] J.M. Bennett, J.P. Cohen, E.M. Flanigen, J.J. Pluth, J.V. Smith, ACS Symp. Ser. 218 (1983) 109.

[7] E.M. Flanigen, B.M. Lok, R.L. Patton, S.T. Wilson, Pure Appl. Chem. 58 (1986) 1351.
[8] K.J. Chao, S.P. Sheu, H.S. Sheu, J. Chem. Soc., Faraday Trans. 88 (1992) 2949.

[9] M.E. Davis, C. Saldarriaga, C. Montes, J. Garces, C. Crowder, Nature 331 (1988) 698.

[10] W. Schmidt, F. Schüth, H. Reichert, K. Unger, Zeolites 12 (1992) 2.

[11] M.J. Duer, H. He, W. Kolodziejski, J. Klinowski, J. Phys. Chem. 98 (1994) 1198.

[12] A. Karlsson, D. Akporiaye, M. Stöcker, Microporous Mater. 4 (1995) 31.

[13] J.R. Anderson, W.R. Jackson, D. Hay, Z. Yang, E.M. Campi, Zeolites 16 (1996) 15.

[14] T. Blasco, M.A. Camblor, A. Corma, J. Pérez-Parienté, J. Am. Chem. Soc. 115 (1993) 11806.

[15] M.A. Camblor, A. Corma, A. Martínez, J. Pérez-Parienté, J. Chem. Soc., Chem. Commun., 1992, p. 589.

[16] D.C. Huybrechts, L.D. Bruycker, P.A. Jacobs, Nature (London) 345 (1990) 240.

[17] R.S. Reddy, J.S. Reddy, R. Kumar, P. Kumar, J. Chem. Soc., Chem. Commun., 1991, p. 413.

[18] J.S. Reddy, P.A. Jacobs, J. Chem. Soc., Perkin Trans. 1 (22) (1993) 2665.

[19] T. Tatsumi, N. Jappar, J. Catal. 161 (1996) 570.

[20] A. Bhaumik, T. Tatsumi, J. Catal. 176 (1998) 305.

[21] B.M. Lok, M.B. Kristoffersen, E.M. Flanigen, EP 121232, 1984.

[22] B.M. Lok, B.K. Marcus, E.M. Flanigen, US Patent 4,500,651, 1985.

[23] N. Ulagappan, V. Krishnasamy, J.C.S. Chem. Commun., 1995, p. 373.

[24] A. Tuel, Zeolites 15 (1995) 228.

[25] A. Tuel, Y. Ben Taarit, J.C.S. Chem Commun., 1994, p. 1667.

[26] B.-Y. Hsu, S. Cheng, Microporous Mesoporous Mater. 21 (1998) 505

[27] F. Babonneau, S. Doeuff, A. Leaustic, C. Sanchez, C. Caritier, M. Verdaguer, Inorg. Chem. 27 (1988) 3166.

[28] A. Tuel, S. Moussa-Khouzami, Y. Ben Taarit, C. Nacchche, J. Mol. Catal. 68 (1991) 45.

[29] A. Thangaraj, R. Kumar, S.P. Mirajkar, P. Ratnasamy, J. Catal. 131 (1991) 294.

[30] P.R.H.P. Rao, A.V. Ramaswamy, Appl. Catal. A 93 (1993) 123.

[31] A. Tuel, Y. Ben Taarit, Appl. Catal. A 102 (1993) 69.

[32] M. Allian, A. Germain, F. Figueras, Catal. Lett. 28 (1994) 409.

[33] J.S. Reddy, S. Sivasanker, P. Ratnasamy, J. Mol. Catal. 71 (1992) 373. 